\title{
Acute renal failure in the obstetric population
}

\author{
Neeta Sarma
}

\begin{abstract}
Corresponding author: Dr. Neeta Sarma, Assistant Professor, Department of Obstetrics and Gynaecology, Silchar Medical College and Hospital, Assam, India; Email : sarma_neeta@rediffmail.com
\end{abstract}

Distributed under Attribution-Non Commercial - Share Alike 4.0 International (CC BY-NC-SA 4.0)

\begin{abstract}
Objectives: The objective of the study is to determine the aetiology and maternal outcome of acute renal failure in pregnancy and postpartum period. Methods: The study was conducted over a period of five years from August 2014 to July 2019. 38 previously healthy women who developed acute renal failure (ARF) during pregnancy or postpartum period were included in the study. Those with known renal disease, diabetes, chronic hypertension, history of renal calculi or urological intervention were excluded. The cases were followed up for a period of six months. Results: 38 patients with pregnancy related ARF were included. The age range was 18 to 39 years (mean $27 \pm 4.1$ years). $2(5.3 \%)$, $16(42.1 \%)$ and $20(52.6 \%)$ women were in the second trimester, third trimester and puerperal period respectively. The different aetiologies were preeclampsia $7(18.4 \%)$, antepartum haemorrhage $4(10.5 \%)$, postpartum haemorrhage $8(21 \%)$, puerperal sepsis $12(31.6 \%)$, intrauterine foetal death $3(7.9 \%)$, acute fatty liver of pregnancy $1(2.6 \%)$, hyperemesis gravidarum $1(2.6 \%)$ and septic abortion 2(5.3\%). Maternal mortality was 5(13.2\%). Of the 33(86.8\%) women who survived, $17(44.7 \%)$ had complete recovery of renal function and $14(36.8 \%)$ had partial recovery. Conclusion: Pregnancy related ARF may have adverse maternal outcome. Approach to each clinical condition leading to it must be individualized and appropriate therapeutic decision is to be taken.
\end{abstract}

Keywords: Acute renal failure, pregnancy, postpartum.

Acute renal failure during pregnancy and the postpartum period is clinically challenging. It often leads to serious consequences upon the mother and the foetus. The condition may be specific and unique to pregnancy or may be coincidental with pregnancy. The causes in early pregnancy include septic abortion, hyperemesis gravidarum; causes in the later part of pregnancy include haemorrhage, particularly abruptio placentae, severe preeclampsia, acute pyelonephritis, DIC following intrauterine foetal death, acute fatty liver of pregnancy whereas puerperal sepsis, haemolytic uremic syndrome, idiopathic postpartum ARF are the causes during the puerperal period. The incidence of pregnancy related ARF is $1-2.8 \%$ in developed countries and $4.2-15 \%$ in developing countries ${ }^{1-3}$. The current incidence of acute kidney injury in pregnancy has shown a declining trend ${ }^{4}$ but still it accounts for $5-20 \%$ of total AKI population ${ }^{5-7}$. Nearly $15-20 \%$ of ARF in India between 1970 to 1980 was attributable to obstetrical complication while latest status is $9-13 \%{ }^{8}$. The incidence has reduced over the last few years because of lesser number of septic abortion cases, improved antenatal care and early diagnosis and prompt management of maternal conditions like preeclampsia and acute pyelonephritis. ARF often leads to renal cortical necrosis which has high morbidity and mortality. Renal biopsy can help to differentiate renal cortical necrosis from acute tubular necrosis which has a better prognosis ${ }^{9}$. This study was

Received: $24^{\text {th }}$ March 2020, Peer review completed: $20^{\text {th }}$ May 2020, Accepted: $26^{\text {th }}$ June 2020.

Sarma N. Acute renal failure in the obstetric population. The New Indian Journal of OBGYN. 2021; 7(2): 177-80. 
The New Indian Journal of OBGYN. 2021 (January-June);7(2)

conducted with the aim to determine the aetiology and maternal outcome of acute renal failure in pregnancy and postpartum period.

\section{Material and methods}

This prospective observational study was conducted at tertiary care hospital over a period of five years from August 2014 to July 2019. 38 women who were previously healthy but developed acute renal failure (ARF) during pregnancy or postpartum period were included in the study. The cases were diagnosed on the basis of having oliguria (urine output $<400 \mathrm{~mL}$ in 24 hours) and raised serum creatinine levels, that is $>2 \mathrm{mg} / \mathrm{dl}$. A detailed history was taken and a thorough clinical examination was done to determine the cause of $\mathrm{ARF}$ and the requirement of dialysis was considered. Those with known renal disease, diabetes or chronic hypertension or with history of renal calculi or urological intervention were excluded. Baseline biochemical investigations were carried out in all patients which included complete blood count, random blood sugar, liver function tests, renal function tests, routine examination of urine and ultrasonography of the abdomen. Selected patients were subjected to investigations like culture and sensitivity tests of blood, urine or vaginal swab, blood coagulation profile etc. as required. The cases were followed up for a period of six months. Those with full recovery of renal function were categorized to have complete recovery, those with impaired renal function but not dialysis dependent were categorized to have partial recovery and those with impaired renal function requiring dialysis even after three months were considered to have end stage renal disease. Percentages were calculated for qualitative (categorical) variables whereas mean $\pm \mathrm{SD}$ were calculated for quantitative (continuous) variables.

\section{Results}

38 patients with pregnancy related ARF were included.

The age range was 18 to 39 years (mean 27+/-4.1years). $2(5.3 \%), 16(42.1 \%)$ and $20(52.6 \%)$ women were in the second trimester, third trimester and puerperal period respectively. $26(68.4 \%)$ belonged to the rural background; $29(76.3 \%)$ of the cases were unbooked (table1).

The different aetiologies were preeclampsia $7(18.4 \%)$, antepartum haemorrhage $4(10.5 \%)$, postpartum haemorrhage $8(21 \%)$, puerperal sepsis $12(31.6 \%)$, intrauterine foetal death $3(7.9 \%)$, acute fatty liver of pregnancy $1(2.6 \%)$, hyperemesis gravidarum $1(2.6 \%)$ and septic abortion 2(5.3\%) (table 2).

\begin{tabular}{lll} 
Table 1: Demographic profile of the patients & \\
\hline Parameter & $\begin{array}{l}\text { Range } \\
\text { (Mean } \pm \text { SD) }\end{array}$ & $\begin{array}{l}\text { Number } \\
\text { (percentage) }\end{array}$ \\
\hline Age (years) & $18-39(27 \pm 4.1)$ & \\
\hline Parity & $0-4(2.6 \pm 1.3)$ & $16(42.1 \%)$ \\
$\quad$ Primigravida & $22(57.9 \%)$ \\
$\quad$ Multigravida & \\
\hline Gestational period at presentation (weeks) & $2(5.3 \%)$ \\
$\quad$ First trimester & $16(42.1 \%)$ \\
Second / Third trimester & $20(52.6 \%)$ \\
$\quad$ Puerperium & $26(68.4 \%)$ \\
\hline Rural & $12(31.6 \%)$ \\
Urban & $9(23.7 \%)$ \\
Booked & $29(76.3 \%)$ \\
Unbooked & $34(89.5 \%)$ \\
Hospital delivery & $4(10.5 \%)$ \\
\hline Home delivery &
\end{tabular}

Table 2: Aetiologies of obstetric ARF

\begin{tabular}{ll}
\hline Aetiologies of obstetric ARF & Number (percentage) \\
\hline Puerperal sepsis & $2(31.6 \%)$ \\
Postpartum haemorrhage & $8(21 \%)$ \\
Preeclampsia- Eclampsia & $7(18.4 \%)$ \\
Antepartum haemorrhage & $4(10.5 \%)$ \\
DIC following intrauterine foetal death & $3(7.9 \%)$ \\
Septic abortion & $2(5.3 \%)$ \\
Acute fatty liver of pregnancy & $1(2.6 \%)$ \\
Hyperemesis gravidarum & $1(2.6 \%)$ \\
\hline
\end{tabular}

Table 3: Laboratory parameters of the cases

\begin{tabular}{llll}
\hline Laboratory parameter & Number & Percentage & Mean value \\
\hline Haemoglobin $<10 \mathrm{~g} / \mathrm{dL}$ & 34 & 89.5 & $7.2 \pm 0.6 \mathrm{~g} / \mathrm{dL}$ \\
Leucocytosis & 14 & 36.8 & $17800 \pm 220 / \mathrm{cu} . \mathrm{mm}$ \\
Thrombocytopenia & 7 & 18.4 & $92000 \pm 1350 / \mathrm{cu} . \mathrm{mm}$ \\
Serum creatinine $>2 \mathrm{mg} / \mathrm{dL}$ & 38 & 100 & $6.25 \pm 2.71 \mathrm{mg} / \mathrm{dL}$ \\
Hyperkalaemia & 19 & 50 & $5.6 \pm 1.2 \mathrm{mEq} / \mathrm{L}$ \\
Hypokalaemia & 12 & 31.6 & $3.01 \pm 1.12 \mathrm{mEq} / \mathrm{L}$ \\
Hypernatremia & 7 & 18.4 & $137.11 \pm 1.26 \mathrm{mEq} / \mathrm{L}$ \\
Hyponatremia & 9 & 23.7 & $124.12 \pm 2.13 \mathrm{mEq} / \mathrm{L}$ \\
Metabolic acidosis & 7 & 18.4 & $7.2 \pm 0.6$ \\
Hyperbilirubinemia & 5 & 13.2 & $5.2 \pm 0.8 \mathrm{mg} / \mathrm{dL}$ \\
Raised FDP & 4 & 10.5 & $11 \mu \mathrm{g} / \mathrm{dL}$ \\
\hline
\end{tabular}

\begin{tabular}{ll} 
Table 4: Management of the cases & \\
\hline Management & Number (Percentage) \\
\hline Mode of delivery & $29(76.3 \%)$ \\
Vaginal delivery & $9(23.7 \%)$ \\
Caesarean section & \\
Treatment offered & $21(55.3 \%)$ \\
Conservative treatment & $17(44.7 \%)$ \\
Haemodialysis & \\
\hline
\end{tabular}

The laboratory parameters of the study group have been demonstrated in table 3. All the patients had raised serum creatinine values. $89.5 \%$ had $\mathrm{Hb}<10 \mathrm{~g} / \mathrm{dL}, \quad 50 \%$ had hyperkalaemia, $36.8 \%$ had leucocytosis, $31.6 \%$ had hypokalaemia. $29(76.3 \%)$ patients of the study group underwent vaginal delivery while the rest had caesarean section. 21(55.3\%) women were treated conservatively whereas $17(44.7 \%$ ) required haemodialysis (table 4 ). 


\begin{tabular}{ll} 
Table 5: Maternal outcome & \\
\hline Maternal Outcome & $\begin{array}{l}\text { Number } \\
\text { (percentage) }\end{array}$ \\
\hline Survivors & $33(86.8 \%)$ \\
Complete recovery & $19(50 \%)$ \\
Partial recovery (not requiring regular dialysis) & $9(23.7 \%)$ \\
End stage renal disease (requiring regular dialysis) & $5(13.2 \%)$ \\
Death & $5(13.2 \%)$ \\
\hline
\end{tabular}

Maternal mortality was 5(13.2\%). Of the 33(86.8\%) women who survived, $19(50 \%)$ had complete recovery of renal function, $9(23.7 \%)$ had partial recovery whereas $5(13.2 \%)$ had end stage renal disease (table 5).

\section{Discussion}

Pregnancy leads to both anatomical and physiological changes in renal and systemic hemodynamics. The kidneys increase in size by about $1-1.5 \mathrm{~cm}$ due to renal vascular and interstitial space volume expansion ${ }^{4}$. The physiological hydronephrosis of pregnancy characterized by a dilation of the calyces, renal pelvis, and ureter occurs in over $90 \%$ of pregnant women ${ }^{10}$. The dilatation of the urinary system is due to the hormonal effects of progesterone, external compression by the gravid uterus, and morphological changes in the ureteral wall. The renal vascular resistance decreases under the effects of maternal hormones like relaxin and progesterone. Renal plasma flow can increase up to $85 \%$ in the second trimester of pregnancy and the GFR can reach $40 \%-50 \%$ of baseline throughout pregnancy ${ }^{4}$ which is responsible for the fall in serum creatinine levels and urinary protein excretion upto $300 \mathrm{mg} /$ day. Systematic vasodilation leads to the stimulation of antidiuretic hormone, resulting in a decrease in plasma osmolality and plasma sodium by $4-5$ $\mathrm{mEq} / \mathrm{L}^{10}$. Minute ventilation increases due to progesteroneinduced stimulation of the central respiratory centre in the brain. This results in a decrease in $\mathrm{pCO}_{2}$ and a mild chronic respiratory alkalosis, which is compensated for renal excretion of bicarbonate ${ }^{4}$.

ARF in pregnancy is variably defined as serum creatinine level more than $0.8 \mathrm{mg} / \mathrm{dL}$ or doubling of serum creatinine to dialysis requirement.

The most common aetiology of ARF in the present study was puerperal sepsis which accounted for $31.6 \%$ of the cases. The other aetiologies were PPH (21\%), preeclampsia (18.4\%), APH (10.5\%), IUFD (7.9\%), septic abortion (5.3\%), hyperemesis gravidarum (2.6\%) and AFLP (2.6\%). Goplani et al ${ }^{1}$ and Aggarwal et al ${ }^{9}$ have also found puerperal sepsis as the commonest aetiology, i.e. $61.42 \%$ and $40 \%$ respectively. In the study by Goplani et al ${ }^{1}$, DIC $(32.5 \%)$, preeclampsia-eclampsia-HELLP (28.5\%), PPH (24.28\%), post-abortal sepsis (20\%), APH (14.28\%) were the other aetiologies. Whereas the other aetiologies in the study by Aggarwal et al ${ }^{9}$ were preeclampsia-eclampsia-HELLP (34\%), APH (24\%), PPH (10\%), septic abortion (6\%) and DIC (4\%). The aetiologies of ARF as found by Hassan et al $^{14}$ in their study were haemorrhage (53.8\%) [PPH 37.2\%, APH $18.6 \%$, puerperal sepsis $(27.1 \%)$, preeclampsiaeclampsia-HELLP (11.6\%), DIC (9.3\%), HUS (2.3\%) and hypotension following hyperemesis gravidarum $(2.3 \%)$. The aetiologies reported by Patel et al ${ }^{12}$ were septicaemia (41.7\%), hypertensive disorders (33.3\%), haemorrhage (13.3\%), abortion (8.3\%), HELLP (1.67\%) and DIC (1.67\%).

Management is clinically challenging as both maternal and foetal aspects need to be taken into consideration. Moreover, the altered cardiovascular and renal physiology during pregnancy adds to the complexity of diagnosis and management necessitating a multidisciplinary approach. The key points in management include stabilization of the patient by maintaining airway, breathing, circulation, treating any underlying cause if apparent, preventing progression of kidney disease by maintaining adequate renal perfusion, monitoring urine output and pulmonary function, stopping or adjusting nephrotoxic drugs, providing supportive care like treating hyperkalaemia, metabolic acidosis, anaemia, or renal replacement therapy/ dialysis and optimizing foetal health, but with priority to maternal health

In our study group, $55.3 \%$ women were treated conservatively whereas $17(44.7 \%)$ required haemodialysis. In the study by Patel et $\mathrm{al}^{12}, 61.7 \%$ and $38.3 \%$ had conservative management and haemodialysis respectively. Najar et al ${ }^{13}$ in their study group reported conservative treatment in $40 \%$ cases, haemodialysis in $32.5 \%$, peritoneal dialysis in $15 \%$ and both in $12.5 \%$.

The maternal mortality of obstetric ARF in our study was $13.2 \%$. In other studies, the maternal mortalities reported were $18.5 \%, 12 \%, 15 \%, 16.2 \%, 9-55 \%, 20 \%, 18 \%$ and $12.5 \%{ }^{1,9,12,14-18}$. In our study, $86.8 \%$ patients survived and $50 \%$ had complete renal recovery, $23.7 \%$ had partial recovery, $13.2 \%$ suffered from end stage renal disease. In the study by Aggarwal et al ${ }^{9}, 88 \%$ patients survived of which $58 \%$ recovered completely whereas $30 \%$ were dialysis dependent. Similarly, in Hassan et al's study ${ }^{14}$, there were $83.7 \%$ surviving patients of which $41.4 \%$ had complete recovery of renal function, $27.9 \%$ had partial recovery whereas $13.9 \%$ required chronic dialysis. In the study by Patel et al ${ }^{12}, 75 \%, 1.7 \%$ and $8.33 \%$ had complete recovery, partial recovery and end stage renal disease respectively. 
The New Indian Journal of OBGYN. 2021 (January-June);7(2)

\section{Conclusion}

Pregnancy related ARF may have adverse maternal outcome. It is important to understand the physiological changes in renal function during pregnancy. Approach to each clinical condition leading to it must be individualized and appropriate therapeutic decision is to be taken keeping in consideration both maternal and foetal interest.

\section{Conflict of interest: None. Disclaimer: Nil.}

\section{References}

1. Goplani KR, Shah PR, Gera DN, Gumber M, Dabhi M, Feroz A, et al. Pregnancy related acute renal failure: A single center experience. Indian J Nephrol. 2008; 18: 17- 21.

2. Kumar SK, Ramakrishna C, Sivakumar V. Pregnancy related acute renal failure. J Obstet Gynecol India 2006;56:308-10.

3. Chugh KS. Etiopathogenesis of acute renal failure in the tropics. Ann Natl Acad Med Sci (India). 1987; 23: 88-99.

4. Prakash J, Ganiger VC . Acute Kidney Injury in Pregnancy-specific Disorders. Indian J Nephrol. 2017 Jul-Aug; 27(4): 258-70.

5. Prakash J, Kumar H, Sinha DK, Kedalaya PG, Pandey LK, Srivastava PK, et al. Acute renal failure in pregnancy in a developing country: Twenty years of experience. Ren Fail. 2006; 28: 309 - 13.

6. Prakash J, Vohra R, Wani IA, Murthy AS, Srivastva PK, Tripathi K, et al. Decreasing incidence of renal cortical necrosis in patients with acute renal failure in developing countries: A single-centre experience of 22 years from Eastern India. Nephrol Dial Transplant. 2007; 22: 1213 - 7.

7. Kumar KS, Krishna CR, Kumar VS. Pregnancy related acute renal failure. J Obstet Gynaecol India. 2006; 56: $308-10$.

8. Chug KS, Singhal PC, Sharma BK, Pal Y, Mathew MT, Dhall K. Acute renal failure of Obstetric origin. Obstet Gynaecol 1976; 48: 642-6.
9. Aggarwal RS, Mishra VV, Jasani AF, Gumber M. Acute renal failure in pregnancy: Our experience. Saudi J Kidney Dis Transpl. 2014; 25: 450 - 5.

10. Rasmussen PE, Nielsen FR. Hydronephrosis during pregnancy: A literature survey. Eur J Obstet Gynecol Reprod Biol. 1988; 27: 249 - 59.

11. Lindheimer MD, Barron WM, Davison JM. Osmoregulation of thirst and vasopressin release in pregnancy. Am J Physiol. 1989; 257(2 Pt 2): F159 - 69.

12. Patel ML, Sachan R, Radheshyam, Sachan P. Acute renal failure in pregnancy: Tertiary care experience from North Indian population. Nigerian Medical Journal. 2013; 54( 3): 191-5.

13. Najar MS, Shah AR, Wani LA, Reshi AR, Banday KA, Bhat MA, et al. Pregnancy related acute kidney injury: A single centre experience from the Kashmir Valley. Indian J Nephrol. 2008; 18: 159-61.

14. Hassan I, Junejo AM, Dawani ML. Etiology and outcome of acute renal failure in pregnancy. J Coll Physicians Surg Pak. 2009; 19: 714-7.

15. Altintepe L, Gezginc K, Tonbul HZ, Çelik C, Güney I, Gezginç ST, et al. Etiology and prognosis in 36 acute renal failure cases related to pregnancy in central Anatolia. Eur J Gen Med. 2005; 2: 110-3.

16. Najar MS, Shah AR, Wani IA, Reshi A R, Banday K A, Bhat M A, et al. Pregnancy related acute kidney injury: A single center experience from the Kashmir Valley. Indian J Nephrol. 2008; 18: 159-61.

17. Akhtar A, Zaffar S, Mehmood A, Nisar A. Obstetrical acute renal failure from frontier province: A 3 years prospective study. J Postgrad Med Inst. 2004; 18: 109-17.

18. Munib S, Khan SJ. Outcomes of pregnancy related acute renal failure. Rawal Med J. 2008; 33:189-92.

\footnotetext{
Neeta Sarma ${ }^{1}$

${ }^{1}$ Assistant Professor, Department of Obstetrics and Gynaecology, Silchar Medical College and Hospital.
} 